\title{
The National Statutes System: A Plea For a New Publication
}

T AWYERS are gradually beginning to recognize the great importance L of statute law. Instead of legislation being regarded as merely sup. plementary to the common law, it is being realized that a large proportion of modern decisions are simply interpretations and applications of statutes, and that legislation is a principal starting point in the development of legal principles.

It is a sad truth, however, that the proper use of statutory material is seriously handicapped by the lack of satisfactory publications. Official pubhications of statutes fail to show the enterprise customarily displayed in the reporting of court decisions. Again, the laws of other states, especially neighboring states, may be involved in a case, or other states may have comparable laws, but how often are these available, either in a private library, or in a public law library? Every lawyer knows the great difficulty, with the existing facilities, of finding all the cases in other states construing identical or substantially identical statutes. This is true largely because it is often practically impossible to find the statutes themselves. And any study of the legislation on a particular subject in the various states meets with the further difficulties inherent in differences of format, and the lack of standard index terms and methods.

It hardly need be pointed out that the Public Affairs Information Service, and the new Library of Congress index, do not begin to solve the problem. These are not even satisfactory indexes: they are incomplete, or do not appear with sufficient promptness.

The ideal solution of the problem seems to be a "National Statutes System," paralleling the deservedly successful "National Reporter System." Similar regional groupings would probably be appropriate, as statutory affinities fit them rather well. Advance sheets would be an important feature of course. Instead of digest headnotes, however, each enactment would have catch-word index lines or paragraphs. If the Reporter System key number device could not be adapted to the new publication, an even more suitable numbering system could be devised without much difficulty. The index paragraphs would be brought together under the appropriate numbers in regional indexes, and in a union index, which latter would be the parallel of the American Digest. A digest of statutes is not recommended, however, because it would not be of much value, as statutes are not subject to satisfactory digesting for law practice or for research purposes. Indexes are the proper 
guides to statutory material, although in this case the index should be constructed on digest principles.

The National Statutes System would print all general laws, as passed by the various state legislatures. Changes in constitutions, and admimstrative, judicial and legislative rules and regulations should also be included. Special laws and resolutions, however, and municipal charters and ordinances could well be excluded; and the printing of bills would be beyond the scope of the publication.

Of course the fact that most state legislatures meet only every other year, with the majority meeting in the odd years, would make the issning of the National Statutes System a bit irregular, but no difficulties should be encountered on that account, as the advance sheets would serve in lean periods until enough material for a regular size volume accuniulated.

The publication of the suggested series could be started on the first of any year, to include all state legislation passed thereafter. It would make the Statutes Systen more serviceable, obviously, if sooner or later preliminary volumes were published giving the constitution and "compiled general laws in force" in each state at the time of the start of the System. Perhaps it would also be found desirable to publish compiled statutes for the various states fron time to time, in the nature of collateral publications, but not as part of the Statutes System itself.

It is believed that the publication of the National Statutes Systen as here suggested would be a profitable venture. This opinion is based on the conviction that practically all purchasers of the Reporter System would take the Statutes System, and many persons, groups and institutions interested in statutes, but not in court decisions, would also be customers. General libraries, and those who are interested in sociology; political science and economics, are among such potential custoners of either a regional unit or the complete Statutes System. The expenses involved in the publication of the series would surely be much less than those of the Reporter System.

The value of a National Statutes System would include not only its usefulness as a practical tool for the practitioner, but also its inportance as a factor in furthering uniform legislation and uniform statutory interpretation, and its immeasurable value in general research. Its potentialities are such that if its publication is deemed too heavy a financial risk for a publisher to take, one of the great foundations should underwrite the venture, as a genuine contribution to the development of law and of social science in general.

Thomas S. Dabagh.

Bureau of PUblic Administration, Untverstry of CaLIForita. 